\title{
Yhteisen maatalouspolitiikan uudistus: Miten suorat tuet jaetaan EU:n jäsenmaiden kesken?
}

\author{
Petri Liesivaara ${ }^{1}$, Ellen Huan-Niemi ${ }^{1}$, Jyrki Niemi ${ }^{1}$

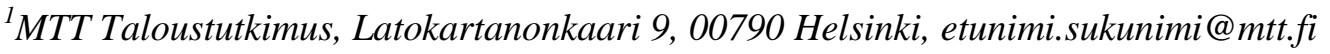

\section{Tiivistelmä}

Euroopan unionin yhteisen maatalouspolitiikan (YMP) on määrä uudistua vuoden 2013 jälkeen. Keskustelua on käyty kiivaasti vuonna 2014 alkavan, uudistetun politiikan suuntaviivoista ja sisällöstä. EU:n komission ehdotus uuden YMP:n muodosta julkaistiin lokakuussa 2011. YMP:n uudistusneuvottelut ovat vahvasti sidoksissa 27 jäsenvaltion välisiin keskusteluihin vuonna 2014 käyttöönotettavasta EU:n pitkän aikavälin budjettirakenteesta. YMP vie yli 40 prosenttia unionin koko budjetista ja siihen liittyvät määrärahat ovat perinteisesti olleet yksi jäsenvaltioiden suurimmista kiistakapuloista. Komission kesäkuussa 2011 tekemässä budjettiehdotuksessa maatalouden rahoitus jäädytettäisiin vuoden 2013 tasolle ja YMP:n osuus koko EU:n budjetista laskisi vuoteen 2020 mennessä 34 prosenttiin.

Tämä tutkimus pureutuu yhteisen maatalouspolitiikan uudistuskeskusteluun tarkastelemalla, kuinka vaihtoehtoiset lähestymistavat vaikuttaisivat maataloustukien jakautumiseen eri jäsenvaltioiden kesken. Päätavoite on arvioida kansallisten määrärahojen suuruudet erilaisissa maatalouspolitiikan uudistusvaihtoehdoissa. YMP-tukien jakoperusteisiin mahdollisesti tehtävien muutosten vaikutusten tuominen esille jo etukäteen lisää ymmärrystä uudistuksen poliittisista haasteista.

Saksa ehdotti vuoden 2010 toukokuussa suorien tukien uudeksi jaoksi vähimmäistuen mallia, jossa EU:n jäsenmaan hehtaarille laskettava tuki olisi vähintään 200 euroa. Mallissa viiden maan (Latvia, Viro, Portugali, Liettua ja Romania) suorat tuet nousisivat 200 euroon. Kahdeksan maan (Slovakia, Espanja, Puola, Iso-Britannia, Suomi, Ruotsi, Tšekin tasavalta ja Luxemburg) suorien tukien määrään ei tulisi muutoksia, sillä niiden tuki on alle EU-27:n keskiarvon. Sen sijaan tukimäärää leikattaisiin noin $2 \%$ yhteensä 14 maassa, joiden hehtaarituki on yli EU-27:n keskiarvon. Ranskan tekemä ehdotus 150 euron vähimmäistuesta nostaisi hehtaaritukia vain kahdessa jäsenmaassa (Viro ja Latvia).

Vaihtoehtona suorien tukien jakamiseksi on esitetty siirtymistä ostovoimakorjattuun tasatukimalliin. Mikäli tukien jaossa otettaisiin eri maiden vaihteleva ostovoima huomioon, Kreikka ja Malta olisivat suurimpia menettäjiä nykyiseen tilanteeseen verrattuna. Saksa olisi selkeä häviäjä ostovoimalla korjatussa mallissa. Sen sijaan Ranska ja 12 muuta maata kuuluvat mallista voittavien maiden joukkoon. Merkittävää on, että peräti yhdeksän uuden jäsenmaan (Romania, Bulgaria, Puola, Unkari, Slovakia, Tšekin tasavalta, Malta, Slovenia ja Kypros) tuki laskisi alle nykyisen tason, mikäli EU:ssa otettaisiin käyttöön ostovoimakorjattu tasatukimalli. Suomi sitä vastoin kuuluisi Latvian, Viron ja Portugalin kanssa suurimpiin voittajiin nykyiseen tilanteeseen verrattuna. Suomen hehtaarikohtainen tuki nousisi yli 330 euron.

EU:n komission esityksessä jäsenmaiden suorat tuet nousisivat tulosten mukaan 13 jäsenmaassa. Suhteessa eniten hehtaarituki nousee Baltian maissa. Euromääräisesti uudistuksen suurimpia voittajia olisivat Iso-Britannia ja Romania. Uudistuksessa suhteellisesti eniten menettäisivät nykytilanteeseen verrattuna Hollanti, Belgia, Italia ja Tanska. Euromääräisesti suurimpia häviäjiä ovat järjestyksessä Italia, Ranska ja Saksa. Suomen hehtaarituki laskee esityksessä 2 euroa nykytilanteeseen verrattuna. EU:n komission esitys suorien tukien uudeksi jaoksi muistuttaa Saksan ja Ranskan esittämää vähimmäistuen mallia.

Rahoituskehyksen tiukkuus on johtanut siihen, että EU:n komissio on päätynyt ehdottamaan ensimmäisen pilarin tukien leikkaamiseen myös niissä maissa, joiden hehtaarituki on alle EU-27:n keskiarvon. Tämä pienentää tarvetta tukien leikkaamiseen Saksassa ja Ranskassa. Vaikka Saksa ja Ranska ovat esityksessä euromääräisesti kolmen eniten häviävän maan joukossa, ehdotus rahoituksen uudelleen jakamiseksi on tehty niiden tarpeita ajatellen.

Asiasanat: EU, yhteinen maatalouspolitiikka, budjetti, tukikriteerit, Suomi 


\section{Johdanto}

Euroopan unionin yhteisen maatalouspolitiikan (YMP) on määrä uudistua vuoden 2013 jälkeen. Keskustelu vuonna 2014 alkavan, uudistetun politiikan suuntaviivoista ja sisällöstä pääsi todenteolla liikkeelle Euroopan komission esitettyä marraskuun 18. päivänä 2010 tiedonantonsa politiikan muutostarpeista (Euroopan komissio 2010). Tiedonanto toi politiikan muutostarpeet ja ehdotetut uudet päälinjat julkiseen keskusteluun ja kuulemiseen ennen varsinaisten lainsäädäntöehdotusten laatimista.

YMP:n uudistusneuvottelut ovat vahvasti sidoksissa 27 jäsenvaltion välisiin keskusteluihin vuonna 2014 käyttöönotettavasta EU:n pitkän aikavälin budjettirakenteesta. Tähän on yksinkertainen syy: YMP kuuluu edelleen unionin menojen ytimeen. Vuoden 2011 heinäkuussa EU:n komission julkaisema budjettiehdotus vuosiksi 2014-2020 jäädyttäisi maatalouteen suunnattujen varojen kokonaismäärän vuoden 2013 tasolle. Näin ollen maatalousmenojen osuus EU:n budjetissa vuonna 2020 olisi enää $34 \%$, kun osuus budjetista on ollut nykyisellä rahoituskaudella noin $40 \%$.

Mitä lähemmäs maaliviivaa yhteisen maatalouspolitiikan uudistusneuvotteluissa tullaan, sitä tarkemmin jäsenvaltiot kiinnittävät huomiota omaan rahoitusrooliinsa: paljonko me maksamme, paljonko me saamme? Käynnissä olevissa YMP-neuvotteluissa rahoituksen jakautumiseen liittyvät asiat nousevat aiempaa selvemmin esille (Huan-Niemi ym. 2011). Jäsenvaltioiden tukimäärät ovat perinteisesti määräytyneet epäsuorasti, kun jäsenvaltiot ovat hyötyneet eri tavoin unionin takaamista interventiohinnoista ja tuotantotuista. Nyt YMP-tuet jaetaan kuitenkin enenevässä määrin jäsenmaiden määrärahoina. Kullakin jäsenvaltiolla on oikeus tiettyyn määrään YMP-rahoitusta, jonka ne voivat käyttää osittain oman harkintansa perusteella.

EU:n komissio julkaisi 7 lainsäädäntöehdotusta 12. lokakuuta 2011, joiden pohjalta Euroopan neuvosta ja EU:n parlamentti aloittivat keskustelut maatalouspolitiikan uudistamisesta. Suorien tukien lainsäädäntöehdotus asettaa lähtökohdat ensimmäisen pilarin tukien jaolle vuoden 2013 jälkeen. Esityksen tavoitteena on aikaisempaa oikeudenmukaisempi suorien tukien jako jäsenmaiden välillä.

Tämä tutkimus pureutuu yhteisen maatalouspolitiikan uudistuskeskusteluun tarkastelemalla, kuinka vaihtoehtoiset lähestymistavat vaikuttavat tukien jakautumiseen eri jäsenvaltioiden kesken. Lisäksi tutkimus tarkastelee EU:n komission ehdotuksen vaikutusta tukien jakautumiseen eri jäsenmaiden kesken. On tärkeää, että YMP-tukien jakoperusteiden vaikutukset tuodaan esiin ja selkeytetään tulevaa YMP-tukiosuuksien jakoa. Samalla lisätään ymmärrystä YMP:n uudistushaasteista.

\section{Aineisto ja menetelmät}

Tutkimuksen aineisto koostuu Euroopan neuvoston asetuksissa määritetyistä suorien tukien enimmäismääristä eri jäsenmaissa (Euroopan komissio 2011a) ja EU:n komission lainsäädäntöesitystä suorien tukien jaoksi vuoden 2013 jälkeen (Euroopan komissio 2011b). Maatalousmaan määränä käytetään Eurostatin tilastoa vuodelta 2007, joka on tuorein tilastoitu vuosi maatalousmaan osalta. Useiden jäsenmaiden maatalousmaan kokonaismäärässä on tilastoissa merkittävää vaihtelua eri vuosien välillä. Tukien jakautuminen siis vaihtelee valittavien alkuarvojen, kuten viitevuotena käytettävän maatalousmaan määrän mukaan. Tästä syystä tutkimuksessa esitetyt tulokset voivat erota esimerkiksi EU:n komission esittämiin lukuihin verrattuna.

Tukien kokonaismäärässä on otettu huomioon modulaation vaikutus jäsenmaiden suorien tukien määrään vuonna 2013. Modulaatiossa ensimmäisen pilarin tukia siirretään toiseen pilariin, joka pienentää jäsenmaiden saamia suoria tukia nykytilanteessa. Jäsenmaiden suorien tukien enimmäismäärä on saatu lainsäädännöstä (Euroopan komissio 2011a). Nykytilannetta kuvaavana viitevuotena käytetään vuotta 2016, koska vuonna 2016 Romanian ja Bulgarian suorien tukien määrä on saavuttanut enimmäistason. Muiden jäsenmaiden suorien tukien enimmäismäärät eivät muutu vuoden 2013 jälkeen.

\section{Tulokset}

Tutkimuksessa tarkastellaan (i) vähimmäistukimallin sekä (ii) ostovoimalla korjatun tukimallin lisäksi (iii) tukien jakautumista EU:n komission tuoreen lainsäädäntöesityksen mukaan.

(i) Vähimmäistuki 
Saksa ehdotti vuoden 2010 toukokuussa suorien tukien uudeksi jaoksi vähimmäistuen mallia, jossa EU:n jäsenmaan hehtaarituki olisi vähintään 200 euroa (Gemeinsamen Agrarpolitik 2010). Mallissa niiden maiden suorien tukien määrä ei muutu, joiden hehtaarituki on EU-27:n keskiarvon ja vähimmäistuen (200 EUR/ha) välissä. Kuviossa 1 on esitetty suorien tukien nykytaso ja vähimmäistuen mallin vaikutus jäsenvaltioiden hehtaarille maksettavaan tukeen. Mallissa viiden maan (Latvia, Viro, Portugali, Liettua ja Romania) suorat tuet nousisivat 200 euroon. Kahdeksan maan (Slovakia, Espanja, Puola, Iso-Britannia, Suomi, Ruotsi, Tšekin tasavalta ja Luxemburg) suorien tukien määrään ei tulisi muutoksia, sillä niiden tuki on alle EU-27:n keskiarvon. Sen sijaan tukimäärää leikattaisiin noin $2 \%$ yhteensä 14 maassa, joiden hehtaarituki on yli EU-27:n keskiarvon. Eniten hehtaarituki alenisi Maltalla ja Kreikassa. Euromääräisesti vähimmäistukimallin suurimpia häviäjiä olisivat luonnollisesti ensimmäisen pilarin tuista suurimman osuuden saajat Ranska, Saksa ja Italia.

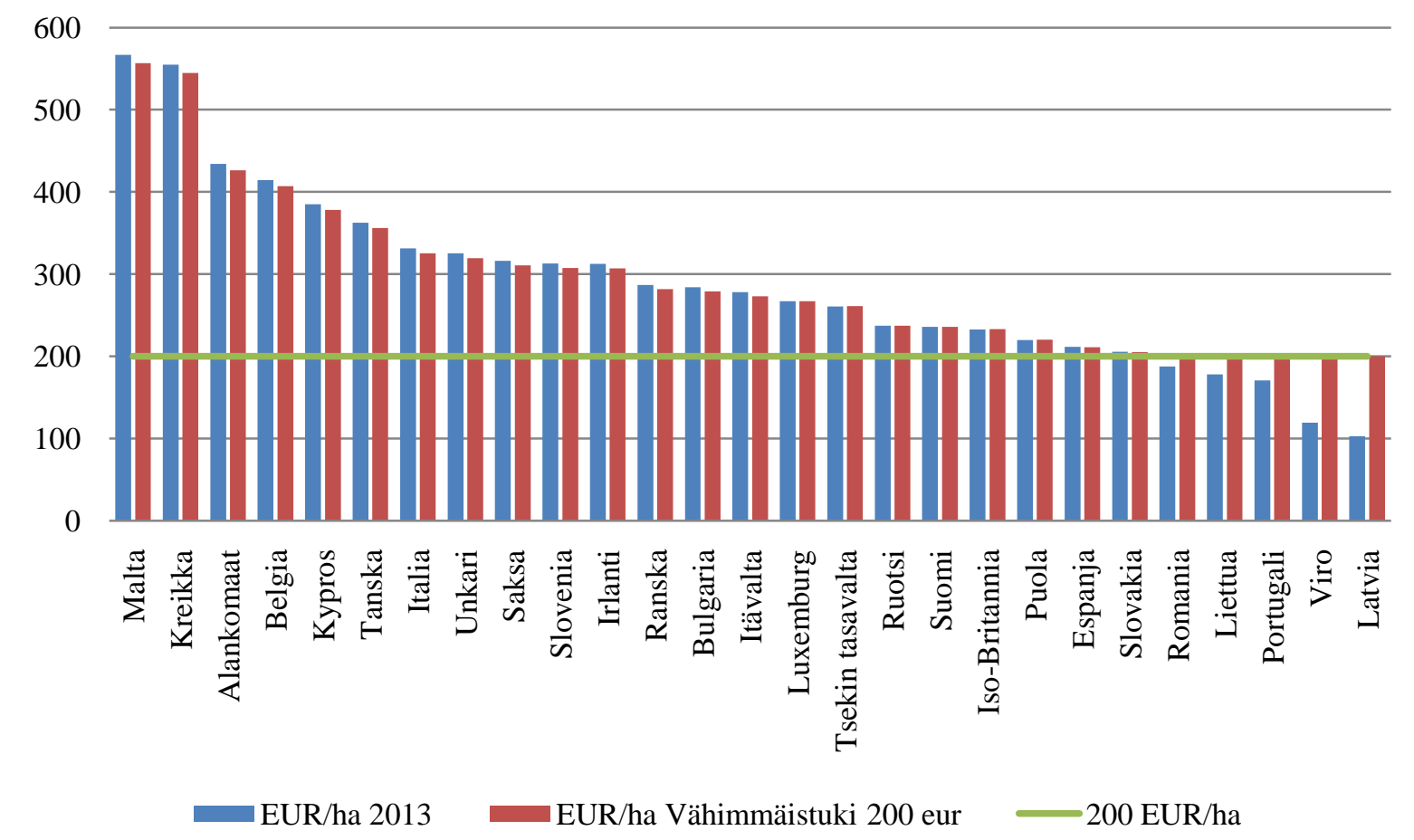

Kuvio 1. EU:n suorien maataloustukien nykyinen taso ja vähimmäistuen tapauksessa (Euroopan komissio 2011a; Eurostat 2011).

Saksan esittämä malli tasoittaisi vain hieman suorien tukien jakoa eri jäsenmaiden välillä. Malli säilyttäisi tukien epäoikeudenmukaisen jaon, jossa jäsenmaiden tukitaso riippuu historiallisista viitesadoista. Vähimmäistuen sijaan kaikille jäsenmaille yhtä suurta tasatukea (euroa/ha) on ehdotettu oikeudenmukaisena järjestelmänä. Tasatuen malli on kuitenkin torjuttu useissa vanhoissa jäsenmaissa. Esimerkiksi Ranskan ja Saksan yhteisen kannan mukaan kaikille jäsenmaille yhteisen tukitason käyttöönottoon ei ole perusteita. Saksa ja Ranska ovat tuoneet esille, että kaikille jäsenmaille samansuuruinen tasatuki ei vastaa taloudellista tilannetta EU:ssa (Franco German position 2010, s. 4). Tasatukea on arvosteltu runsaasti siitä, ettei se ota maiden vaihtelevaa ostovoimaa huomioon. Ostovoiman huomioonottaminen tuen tasossa toimisi hyvin taloudellisten tilanteiden tasaajana eri maiden välillä.

\section{(ii) Ostovoimalla korjattu tasatuki}

Eri maiden ostovoimien vertailu perustuu ostovoimalla korjatun tasatuen mallissa maiden vaihteleviin ostovoimapariteetteihin. Ostovoimapariteetti on samojen tuotteiden tai palvelujen hintojen suhde eri jäsenmaissa. Ostovoimapariteetin suhde valuuttakurssiin taas kertoo, kuinka paljon eri maiden hintatasot vaihtelevat EU:n keskiarvosta. Tätä suhdetta kutsutaan hintatasoindeksiksi. Esimerkiksi jos maan hintatasoindeksi on 110, sen hintataso on $10 \%$ korkeampi kuin EU:ssa keskimäärin. 
Hintatasoindeksi voi siis joko nostaa tai laskea maan maataloustukea sen mukaan, kuinka paljon sen hintataso poikkeaa EU:n keskiarvosta. Tasatuen tasona ostovoimalla korjatun tasatuen laskennassa on käytetty EU-27:n hehtaarituen keskiarvoa vuonna 2013 (268 euroa/hehtaari). Kuviossa 2 verrataan ostovoimalla korjatun tasatuen mallin hehtaaritukea nykyiseen tukitasoon eri jäsenmaissa.

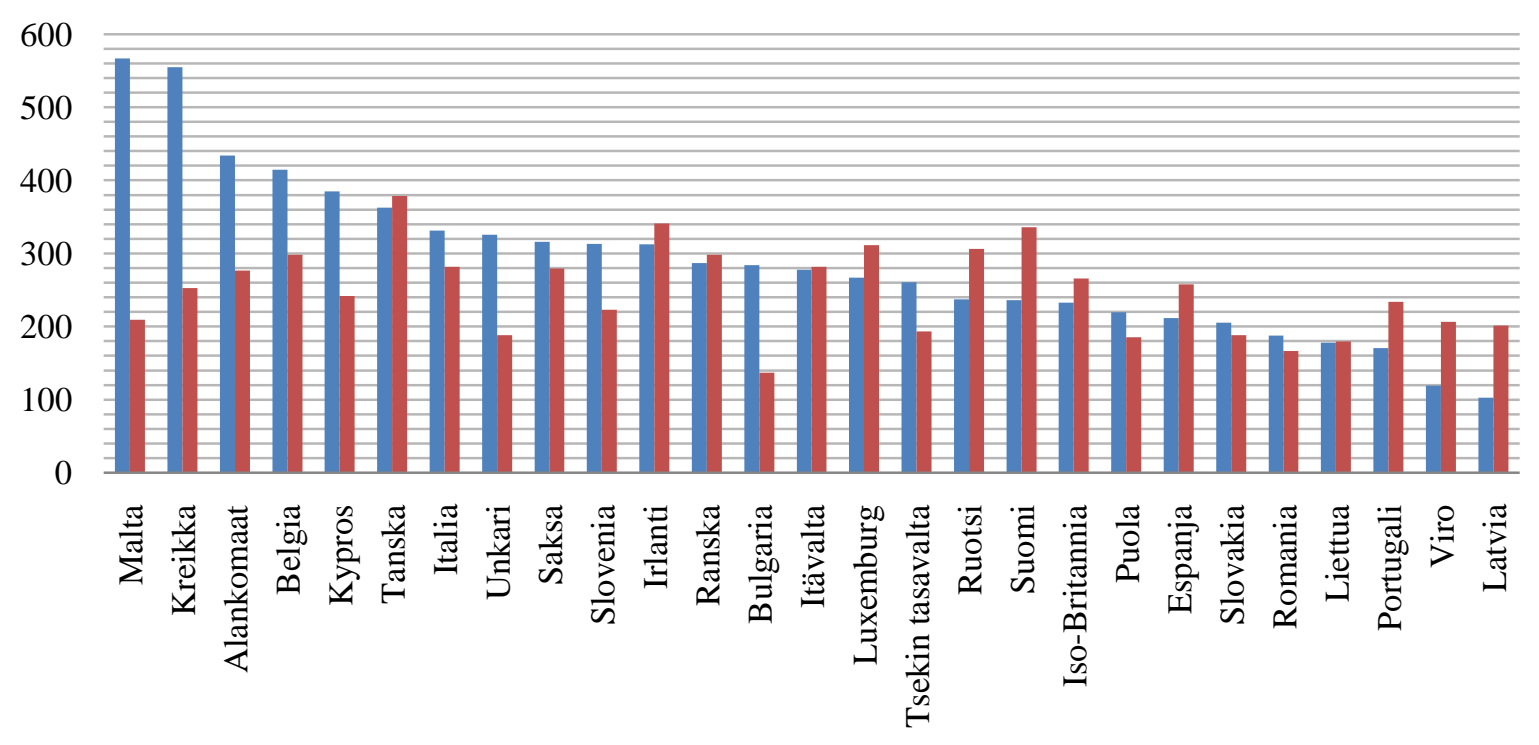

- EUR/ha 2013 Ostovoimalla korjattu tasatuki EUR/ha

Kuvio 2. Ostovoimalla korjattu tasatuki ja nykyinen tukitaso (Euroopan komissio 2011a; Eurostat 2011).

Mikäli tasatuessa otetaan eri maiden ostovoima huomioon, Suomen hehtaarikohtainen tuki nousisi 336 euroon, joka on 100 euroa korkeampi kuin nykyinen tukitaso. Suomi siis kuuluu mallista eniten voittavien maiden joukkoon. Ostovoimalla korjatun tasatuen mallissa merkittävää on, että yhdeksän uuden jäsenmaan (Romania, Bulgaria, Puola, Unkari, Slovakia, Tšekin tasavalta, Malta, Slovenia ja Kypros) tuki laskisi alle tuen nykytason. Uusista jäsenmaista siis vain Baltian maat hyötyisivät ostovoimalla korjatusta tasatuen mallista.

Ostovoiman huomioon ottaminen sen sijaan hyödyttäisi kymmentä vanhaa jäsenmaata. Vanhoista jäsenmaista vain Espanjan (258 euroa), Kreikan (252 euroa) ja Portugalin (234 euroa) tukitaso jää alle EU:n keskiarvon. Nykyiseen tilanteeseen verrattuna Saksa olisi selkeä häviäjä. Saksan lisäksi Italia, Belgia ja Alankomaat kuuluvat mallista häviävien maiden joukkoon. Euromääräisesti mallista eniten häviäviä maita olisivat järjestyksessä Kreikka, Saksa ja Italia. Sen sijaan Ranskan, Irlannin, Tanskan, Ruotsin ja Luxemburgin kokonaistukimäärä nousisi nykytilanteeseen verrattuna. Ostovoimalla korjattu tukimalli pienentäisi tukieroja eri maiden välillä, mutta malli ei poistaisi tukieroja uusien ja vanhojen jäsenmaiden väliltä.

(iii) EU:n komission esitys suorien tukien jaosta

Lokakuun 12. päivänä 2011 EU:n komissio julkaisi ehdotuksensa YMP:n muodosta vuosille 20142020. Uudistus koostuu seitsemästä lainsäädäntöesityksestä, joista yksi käsittelee suorien tukien muotoa ja sisältää esityksen rahoituksen jakautumisesta jäsenvaltioden välillä (Euroopan komissio 2011b). EU:n komission esittämä suorien tukien jako jäsenmaiden kesken ottaa huomioon ehdotuksen unionin rahoituskehyksestä vuosille 2014-2020, jossa YMP:n varat pidetään vuoden 2013 tasolla koko rahoituskauden 2014-2020 ajan. Ehdotuksessa suorien tukien tasapuolisempi jako toteutettaisiin nostamalla niiden jäsenvaltioiden tukitasoa, joiden hehtaarille maksettava tuki on tällä hetkellä alle 90 $\%$ EU-27:n keskiarvosta. Hehtaarituen eroja tasataan kolmanneksella suhteessa 90 \% EU:n keskiarvoon. 


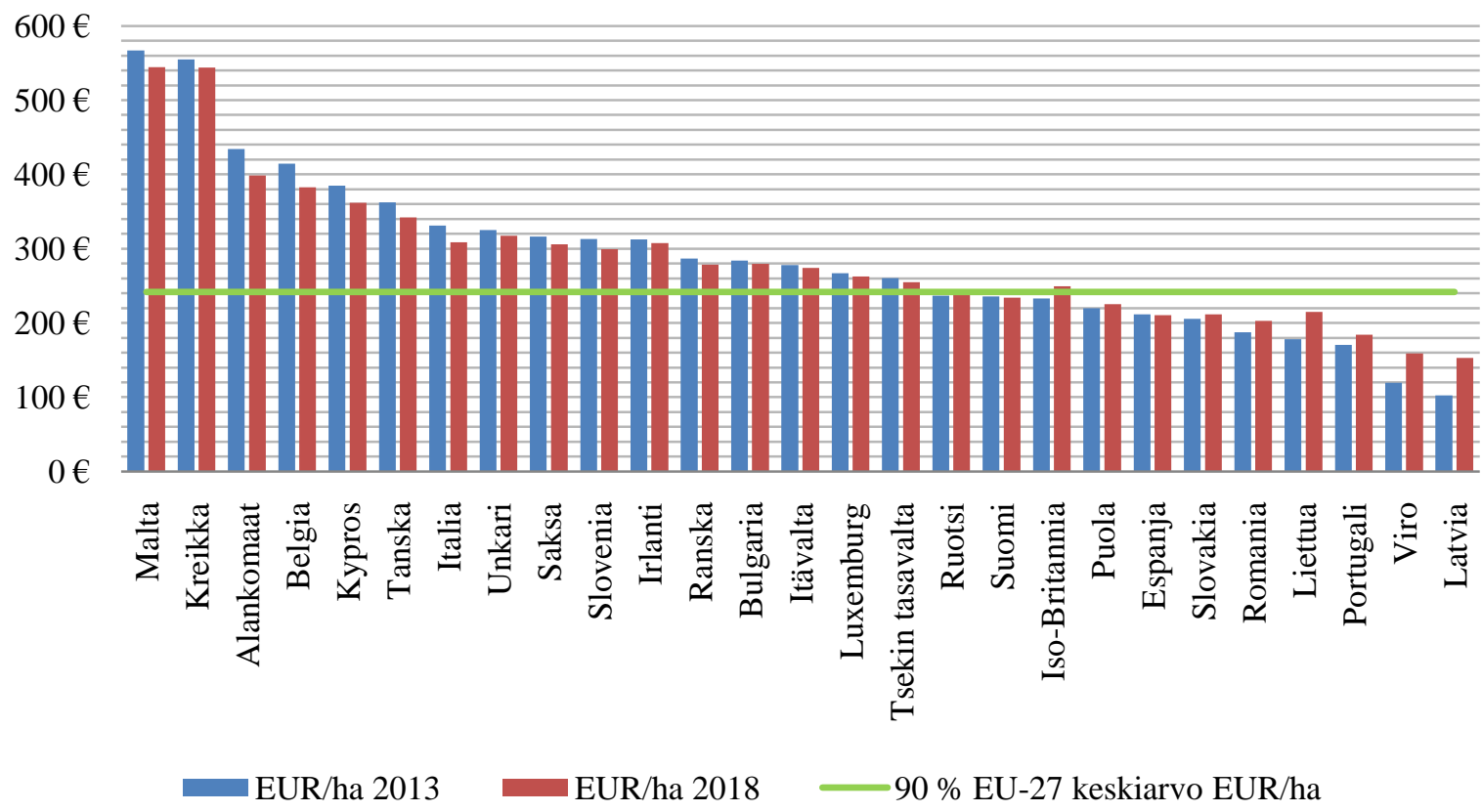

Kuvio 3. EU:n suorat tuet (EUR/ha) nykytilanteessa, EU:n komission esityksen mukaan ja $90 \%$ EU27:n hehtaarituen keskiarvosta (Euroopan komissio 2011a; Euroopan komissio 2011b; Eurostat 2011).

Kuviossa 3 on esitetty kuinka jäsenvaltioiden saama hehtaarituki muuttuisi EU:n komission esityksessä verrattuna nykytilanteeseen. Suomen asema ei merkittävästi muutu EU:n komission esityksessä. Koska Suomessa hehtaarituki on alle 90 \% EU-27:n keskiarvosta, Suomen suorien tukien kokonaismäärä nousee 2,4 miljoonaa euroa nykytilanteeseen verrattuna tukien tasaamisesta johtuen. Tulevan rahoituskauden budjetin tiukkuus on kuitenkin johtanut siihen, että EU:n komissio on päätynyt ehdottamaan tukien leikkausta 1,3\% kaikissa jäsenmaissa. Tämä tarkoittaa sitä, että tukia leikataan myös niissä maissa, joiden tukitaso on alle EU-27:n keskiarvon. Suomessa budjetin leikkauksesta aiheutuu 7 miljoonan euron menetys. Suomen suorien tukien määrä siis laskisi noin 4,6 miljoonaa euroa vuodessa. Tämä vastaa noin 2 euron menetystä hehtaarilta nykytilanteeseen verrattuna.

Komission esitys nostaisi jäsenmaiden suoria tukia tulosten mukaan 13 jäsenmaassa. Suhteessa eniten hehtaarituki nousee Baltian maissa. Euroissa laskettuna uudistuksesta eniten hyötyisivät Puola, Iso-Britannia ja Romania. Suhteellisesti eniten nykytilanteeseen verrattuna menettäisivät Hollanti, Belgia, Italia ja Tanska. Euromääräisesti suurimpia häviäjiä olisivat Italia, Ranska ja Saksa.

EU:n komission esitys suorien tukien uudeksi jaoksi muistuttaa lopputulokseltaan Saksan ja Ranskan esittämää mallia vähimmäistuesta (kuvio 4). Ranska ehdotti 150 euron vähimmäistukea sen jälkeen, kun Saksa oli julkaissut oman ehdotuksen 200 euron vähimmäistuesta toukokuussa 2010 (Gemeinsamen Agrarpolitik 2010). EU-27:n pienimmät hehtaarituet ovat Latviassa ja Virossa. Nykyinen EU:n komission esitys nostaa näiden maiden hehtaarituen lähelle 150 euroa. 


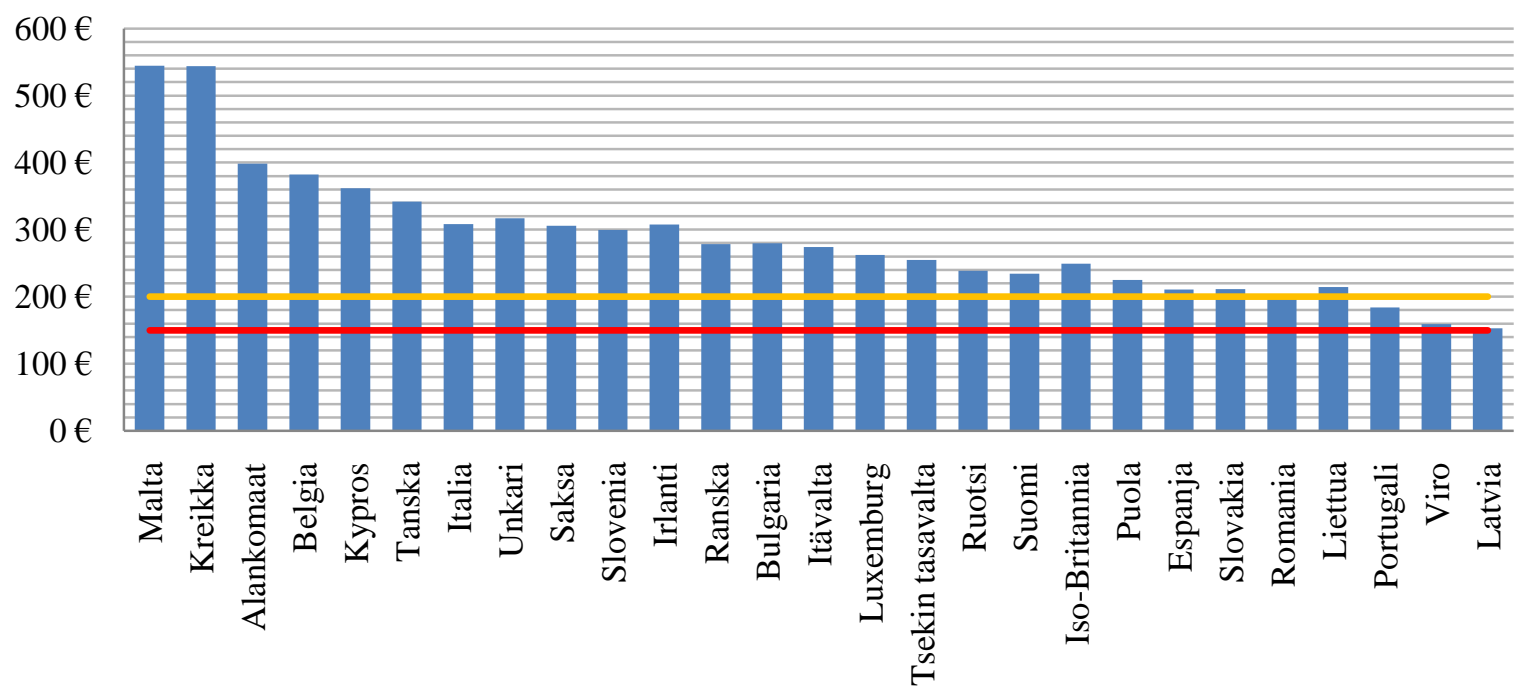

EUR/ha 2018

_Laksan esitys vähimmäistuki 200 EUR/ha

— Ranskan esitys vähimmäistuki 150 EUR/ha

Kuvio 4. Suorat tuet (EUR/ha) EU-27 jäsenmaissa EU:n komission esityksen mukaan sekä Saksan ja Ranskan ehdotukset vähimmäistuesta (Euroopan komissio 2011b; Eurostat 2011).

\section{Johtopäätökset}

Ensimmäisen pilarin suorien tukien jakoa jäsenmaiden kesken tasoitetaan vuodesta 2014 lähtien. YMP:n uudistamisen ympärillä käytävässä keskustelussa on ollut esillä useita vaihtoehtoja tukien uudelleen jakamiseksi. Erilaisten mallien mukaan niin sanottujen uusien jäsenmaiden hehtaarikohtainen tukimäärä kasvaisi. Tukimäärän kasvu rahoitettaisiin laskemalla tukitasoja vanhoissa jäsenmaissa. Suomen hehtaarikohtainen tukimäärä on lähellä EU-27:n keskiarvoa, joten erilaisten mallien vaikutus Suomen tukitasoon on pieni. Ostovoimalla korjatussa tasatukimallissa Suomi olisi kuitenkin selkeä voittaja. EU:n komission esityksessä Suomen suorien tukien kokonaismäärä laskee nykyiseen tilanteeseen verrattuna.

EU:n komission vuoden 2013 jälkeistä aikaa koskevassa lainsäädäntöesityksessä tukitasoja tasoitetaan eri jäsenmaiden välillä maltillisesti. Maatalouden rahoitus tullaan pitämään vuoden 2013 tasolla EU:n rahoituskaudella 2014-2020. Vaikka Suomen hehtaarituki on alle 90 \% EU-27:n keskiarvon, Suomen saamien suorien tukien kokonaismäärä laskee EU:n komission ehdotuksessa nykytilanteeseen verrattuna. Rahoituskehyksen tiukkuus on johtanut siihen, että EU:n komissio on päätynyt ehdottamaan ensimmäisen pilarin tukien leikkaamiseen myös niissä maissa, joiden hehtaarituki on alle EU-27:n keskiarvon.

EU:n komission näkemyksen mukaan useamman maan on osallistuttava tukitasojen nostamisen rahoittamiseen niissä maissa, joiden tukitasot ovat tällä hetkellä alle EU:n keskiarvon. Tasaleikkaus vähentää jäsenmaiden suoria tukia 1,3\% nykytilanteeseen verrattuna. Tämä pienentää tarvetta tukien leikkaamiseen suurissa jäsenmaissa. Vaikka Saksa ja Ranska ovat esityksessä euromääräisesti kolmen eniten häviävän maan joukossa, ehdotus rahoituksen uudelleen jakamiseksi on tehty niiden tarpeita ajatellen. Ensimmäisen pilarin tukien jako voi vielä muuttua muun muassa sen mukaan, millaiseksi kauden 2014-2020 rahoituskehys ja EU:n komission ehdotus muotoutuu Euroopan parlamentin ja neuvoston käsittelyssä.

\section{Kirjallisuus}

Euroopan komissio 2010. Communication from the commission to the European parliament, the council, the European economic and social committee and the committee of the regions. The CAP towards 2020: Meeting the food, natural resources and territorial challenges of the future. Brussels, 18.11.2010. $\operatorname{COM}(2010) 672$ final. 
Euroopan komissio 2011a. Commission Regulation (EU) No 307/2011 of 29 March 2011 amending Annex IV and Annex VIII to Council Regulation (EC) No 73/2009 establishing common rules for direct support schemes for farmers under the common agricultural policy.

Euroopan komissio 2011b. Proposal for a Regulation of the European Parliament and the Council establishing common rules for direct payments to farmers under support schemes within the framework of common agricultural policy. Brussels 19.10.2011 COM (2011) 625 final/2.

Eurostat 2011. Eurostatin tilastot. Saatavissa internetissä:

http://epp.eurostat.ec.europa.eu/portal/page/portal/statistics/search_database

Franco German position 2010. Franco German position for a strong Common Agricultural Policy beyond 2013 - New challenges and expectations for food, biomass and environment. Bundesministerium für Ernährung, Landwirtschaft und Verbaucherschutz, Ministre de L'Alimentation, De L’Agriculture Et De La Peche. 14.09.2010

Gemeinsamen Agrarpolitik 2010. Weiterentwicklung der Gemeinsamen Agrarpolitik (GAP) nach 2013. 12. Mai 2010.

Huan-Niemi, E., Kull, M., Liesivaara, P. \& Niemi, J. 2011. Yhteisen maatalouspolitiikan uudistus: Vaihtoehtoisten tukikriteerien vaikutukset jäsenmaiden rahoitusosuuksiin? MTT Raportti 17 (2011). 39 s. ISBN 978-952-487-316-1 